$16^{\text {th }}$ International Congress of Metrology, 02007 (2013)

DOI: $10.1051 /$ metrology/201302007

(C) Owned by the authors, published by EDP Sciences, 2013

\title{
Calibration and use of syringe pumps
}

\author{
Elsa Batista ${ }^{1, \mathrm{a}}$, Nelson Almeida ${ }^{1}$, Eduarda Filipe ${ }^{1}$, Anselmo Costa $^{2}$ \\ ${ }^{1}$ IPQ - Instituto Português da Qualidade, Rua António Gião, 2, 2829-513 Caparica, Portugal \\ ${ }^{2} \mathrm{HGO}$ - Hospital Garcia de Orta, Av. Torrado da Silva, 2801-951 Almada, Portugal
}

\begin{abstract}
There are several types of infusion instruments used for drug delivery, e.g. syringe pumps and infusion pumps, with different capacities according to their use and applied therapeutic. In order to ensure the traceability of these flow and volume measuring equipment is necessary to use suitable calibration methods and standards. Current calibration services of microflow do not go below $16 \mu \mathrm{L} / \mathrm{min}$ ( $4 \%$ uncertainty), whereas the lowest comparison between primary standards has been of $100 \mathrm{~mL} / \mathrm{min}$, hence, below the latter flow rate, the primary standards have not been validated. Also there are several influence factors in the use of drug delivery devices that are not yet studied in detail. Therefore, a need for the development of a research project in the scope of the EMRP - European Metrology Research Programme, was identified. In order to validate the microflow gravimetric calibration method, developed at the Volume Laboratory of the Portuguese Institute for Quality in the scope of the participation in the EMRP project - Metrology for drug delivery (MeDD), several infusion instruments supplied by the Hospital Garcia de Orta/ Neonatology Service were tested at different volumes and rates. From the obtained results, it can be implemented several improvements for the use and calibration procedures.
\end{abstract}

\section{Introduction}

Infusion instruments are used in clinical environment for nutrition and hydration of patients and can also have therapeutically functions, namely drug delivery. In several international studies [1] it was verified that the infusion technique is a technology with underestimated risks due to several influence factors, namely the use of very small flow $(300 \mathrm{~nL} / \mathrm{min})$ in preterm babies, multipump administration with the use of several administration lines and the individual variables of the different drugs.

Typically, for a proper drug delivery the total delivered volume (mass) is the most important parameter. However, there are a significant percentage of drugs for which the actual flow rate is very important for a proper patient treatment.

For most critical drugs, a $5 \%$ uncertainty in flow rate is sufficient. There is doubt, however, whether this uncertainty criterion is satisfied for (ultra-) low flow rates and for multi-pump infusion. Also, the overall drug delivery characteristics are not properly known. The clinically relevant drug delivery characteristics are start-up time, flow rate stability and response time to occlusion-alarm. An incomplete knowledge of these characteristics can also result in unexpected flow rates and/or flow rate fluctuations.

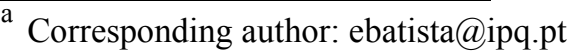

Several other problems associated with these instruments were observed, namely, under or over administration of the therapeutic, incorrect data integration/structural failure, operation interruption without alarm, incorrect warning of block and failure in the alarm of identified condition.

\subsection{EMRP-MeDD}

The European Association of National Metrology Institutes, EURAMET, started, in 2007, the European Metrology Research Programme - EMRP, supported by the 7th Framework Program of the European Commission. This Program opens a call every year for Joint Research Projects (JRPs), in strategic themes defined by EMRP. These JRPs are developed by the member countries and can be supported by Universities and other entities that work in scientific areas were measurements are critical and fundamental.

In 2011, one of the chosen JRP subjects was "Health". This choice had the main purpose of developing science and technology in the field of health, specifically, to assure the traceability of clinical data, allowing the comparability of diagnostic and treatment information.

The JRP "MeDD - Metrology for Drug Delivery" was accepted for the development of a primary standard for flow measurements between $150 \mu \mathrm{L} / \mathrm{min}$ and $1 \mathrm{~nL} / \mathrm{min}$. This JRP will also characterize the flow meters and flow 
generators already in the market and will assure the traceability of the syringe pumps measurements used in drug delivery. This work will allow in the future the increase of efficiency and trust in the flow delivered by the drug delivery systems, which are fundamental instruments for patient therapy.

In order to validate the microflow gravimetric calibration method developed at the Volume Laboratory (LVO) of the Portuguese Institute for Quality (IPQ), and in the frame of LVO participation in the EMRP MeDD project, several infusion instruments supplied by the Hospital Garcia de Orta/ Neonatology Service were tested at different volumes and flow rates.

\section{Methods and Instrumentation}

There are several methods for calibration/verification of infusion devices: the comparison method "in situ" using a flowmeter and the gravimetric method used in the laboratory [2]. The later was the one used in this work.

\subsection{Gravimetric method}

The gravimetric method consists on weighing an amount of water delivered or contained from/in a volume instrument. A conversion is then performed from mass to volume at a reference temperature of $t_{0}$ (normally $20^{\circ} \mathrm{C}$ ). The recommended equation is described in ISO 4787 standard:

$$
V_{0}=\left(I_{L}-I_{E}\right) \times \frac{1}{\rho_{w}-\rho_{A}} \times\left(1-\frac{\rho_{A}}{\rho_{B}}\right) \times\left[1-\gamma\left(t-t_{0}\right)\right]
$$

\subsubsection{Flow measurement}

The flow measurement can be done by a static or a dynamic method. The static method is generally used for the calibration of volumetric meters and consists of the measurement of a volume at a preset flow rate. The dynamic method used in the calibration of flowmeters consists in the determination of the mass or volume per unit of time. In this text we describe the dynamic gravimetric method of flow measurement.

\subsubsection{Calibration procedure for infusion instruments}

The calibration procedure of infusion instruments is based on the IEC 60601-2-24 [3]. The syringe is filled with ultra-pure water without air entrapment. A sufficient amount of water is passed to the tube in order to remove all air bubbles. The flow to be calibrated is then programed in the pump and the water is collected in a balance (figure 1). The volumetric flow is directly calculated by a computer program written in "LabVIEW".

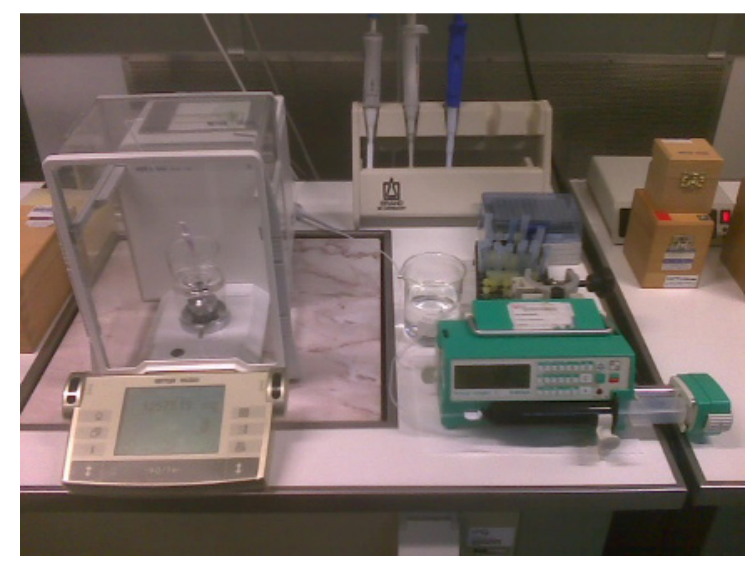

Figure 1. Experimental assembly for the calibration of infusion instruments

The obtained volumetric flow is determined using equation 2 .

$$
Q=\frac{1}{t_{f}-t_{i}}\left[\frac{\left(1-\frac{\rho_{A}}{\rho_{B}}\right) I_{f}[1-\gamma(T-20)]}{\rho_{w}-\rho_{B}}-\frac{\left(1-\frac{\rho_{A}}{\rho_{B}}\right) I_{i}[1-\gamma(T-20)]}{\rho_{w}-\rho_{A}}+\delta V_{\text {evap }}\right]
$$

\subsection{Type of infusion instrument used}

There are several types of infusion instruments used for drug delivery, with different capacities according to their use and applied therapeutic, e.g. syringe pumps and infusion pumps. In this work the syringe pump perfusor compact $\mathrm{S}$ from BBraun was used. The instrument characteristics are presented in table 1.

Table 1. Perfusor Compact S caracteristics

\begin{tabular}{|c|c|}
\hline \multicolumn{2}{|c|}{ Perfusor Compact S } \\
\hline Flow range & $10,1 \mathrm{~mL} / \mathrm{min}-999,9 \mathrm{~mL} / \mathrm{min}$ \\
\hline Resolution & $0,01 \mathrm{~mL} / \mathrm{h}$ \\
\hline Precision & $2,5 \%$ \\
\hline
\end{tabular}

\section{Analysis of results}

\subsection{Calibration of syringe pumps}

Several calibrations were performed at a flow rate of $1 \mathrm{~mL} / \mathrm{h}$ using the Perfusor Compact $\mathrm{S}$, with $50 \mathrm{~mL}$, $20 \mathrm{~mL}$ and $5 \mathrm{~mL}$ syringes. Three repetitions for each syringe was performed in order to assess the repeatability of the instrument, the results are presented in the following tables and figures: 
Table 2. Test results with $50 \mathrm{~mL}$ and $5 \mathrm{~mL}$ syringes

\begin{tabular}{|c|c|c|c|c|}
\hline $\begin{array}{c}\text { Nominal } \\
\text { flow }\end{array}$ & Syringe & $\begin{array}{c}\text { Obtained } \\
\text { flow } \\
(\mathbf{m L} / \mathbf{h})\end{array}$ & $\begin{array}{c}\text { Error } \\
\mathbf{( \% )}\end{array}$ & $\begin{array}{c}\text { Uncertainty } \\
\mathbf{( \% )}\end{array}$ \\
\hline \multirow{2}{*}{$1 \mathrm{~mL} / \mathrm{h}$} & \multirow{2}{*}{$50 \mathrm{~mL}$} & 0,9839 & 1,61 & 0,12 \\
\cline { 3 - 5 } & & 0,9888 & 1,12 & 0,21 \\
\cline { 3 - 5 } & \multirow{2}{*}{$5 \mathrm{~mL}$} & 0,9983 & 1,64 & 0,17 \\
\cline { 3 - 5 } & & 0,9987 & 0,13 & 0,34 \\
\cline { 3 - 5 } & & 0,9989 & 0,11 & 0,41 \\
\hline
\end{tabular}

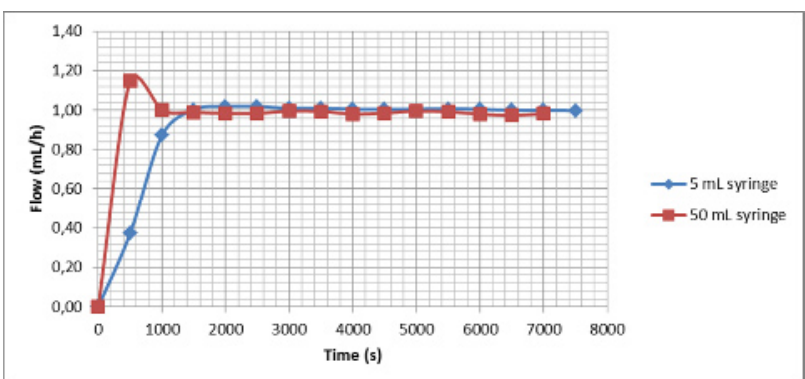

Figure 2. Flow measurements with $5 \mathrm{~mL}$ and $50 \mathrm{~mL}$ syringe. The syringe of $50 \mathrm{~mL}$ showed an abnormal stabilization situation due to its characteristics.

Table 3.Test results with $20 \mathrm{~mL}$ syringe

\begin{tabular}{|c|c|c|c|c|}
\hline $\begin{array}{c}\text { Nominal } \\
\text { flow }\end{array}$ & Syringe & $\begin{array}{c}\text { Obtained } \\
\text { flow } \\
(\mathbf{m L} / \mathbf{h})\end{array}$ & $\begin{array}{c}\text { Error } \\
\mathbf{( \% )}\end{array}$ & $\begin{array}{c}\text { Uncertainty } \\
\mathbf{( \% )}\end{array}$ \\
\hline \multirow{2}{*}{$1 \mathrm{~mL} / \mathrm{h}$} & \multirow{2}{*}{$20 \mathrm{~mL}$} & 1,1050 & 10,5000 & 0,43 \\
\cline { 3 - 5 } & & 1,0896 & 8,9600 & 0,46 \\
\cline { 3 - 5 } & & 1,1050 & 10,5000 & 0,42 \\
\hline
\end{tabular}

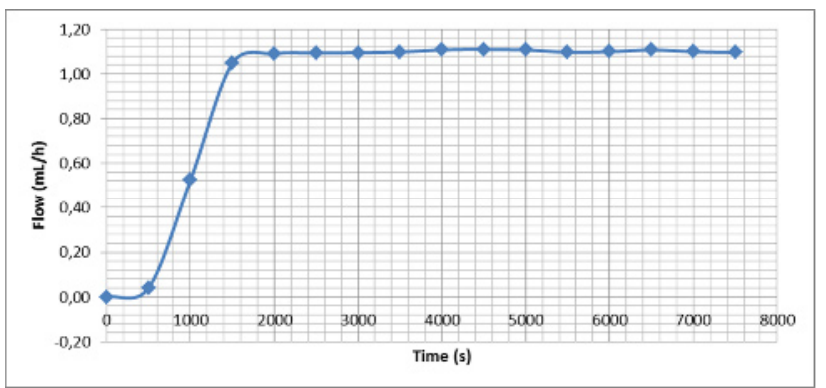

Figure 3. Flow measurements with $20 \mathrm{~mL}$ syringe

For the $50 \mathrm{~mL}$ and $5 \mathrm{~mL}$ syringe the errors are always smaller than $2,5 \%$ (value described by the manufacturer as the maximum permissible error) [4].

However for the $20 \mathrm{~mL}$ syringe the obtained results had an error about $10 \%$ which is much larger than the maximum permissible error as described by the manufacturer.

This situation was investigated and it was observed that the system had an incorrect code for the $20 \mathrm{~mL}$ disposable syringe. The correct code was then inserted and the results are now within the MPE of the manufacturer (see Table 4):

Table 4. Test results for the $20 \mathrm{~mL}$ syringe with the correct code

\begin{tabular}{|c|c|c|c|c|}
\hline $\begin{array}{c}\text { Nominal } \\
\text { flow }\end{array}$ & Syringe & $\begin{array}{c}\text { Obtained } \\
\text { flow } \\
(\mathbf{m L} / \mathbf{h})\end{array}$ & $\begin{array}{c}\text { Error } \\
\mathbf{( \% )}\end{array}$ & $\begin{array}{c}\text { Uncertainty } \\
\mathbf{( \% )}\end{array}$ \\
\hline \multirow{2}{*}{$1 \mathrm{~mL} / \mathrm{h}$} & \multirow{2}{*}{$20 \mathrm{~mL}$} & 0,9990 & 0,1000 & 0,38 \\
\cline { 3 - 5 } & & 0,9890 & 1,1000 & 0,36 \\
\cline { 3 - 5 } & & 0,9964 & 0,3600 & 0,40 \\
\hline
\end{tabular}

One can also verify that for a flow of $1 \mathrm{~mL} / \mathrm{h}$ the suitable syringe with the smaller error is the one of $5 \mathrm{~mL}$.

The calibration results have a good repeatability with uncertainties between $0,1 \%$ e $0,4 \%$. The flow stabilizes after 20 minutes of testing.

\section{Conclusion}

The regular maintenance and calibration of instruments infusion allows the identification and correction of errors, minimizing potential risk situations for the patient. The Volume Laboratory of IPQ recently implemented the gravimetric determination of flow with an uncertainty on the order of $0,5 \%$.

During the development and validation of the standard for flow measurements several tests were performed with different infusion instruments used by the Hospital Garcia de Orta. These tests allowed comparing the results of the accuracy of instruments, obtained experimentally with those indicated by the manufacturers and also identified an incorrect programing situation effect.

We can conclude that it is essential to follow the manufacturer instructions and specifications, specially the ones related to the consumables in use with the infusion systems, in order to prevent significant errors.

\section{References}

1. A. Teimersma, 'Effect of flow fluctuations during administration of vasoactive drugs with infusion pumps'. University Twente, Enschede, (April 2011)

2. ISO 4787:2010 - Laboratory glassware - Volumetric glassware - Methods for use and testing of capacity

3. IEC, IEC 60601-2-24 (1998). Medical electrical equipment - Part 2-24: Particular requirements for the safety of infusion pumps and controllers, Suíça, 1998

4. B. Braun Medical. Lda, Perfusor Compact S Instructions Manual, B $\mid$ BRAUN Hospital Care 
This project is carried out with funding by the European Union under the EMRP

\section{Acknowledgments}

The authors would like to thank Luis Ribeiro and João Gala for their valid contribute to this paper. 